\title{
Optimal Placement of Multi DG Unit in Distribution Systems Using Evolutionary Algorithms
}

\author{
P. Sobha Rani ${ }^{1}$, A.Lakshmi Devi ${ }^{2}$ \\ Assoc. Professor, Dept. E.E.E.,N.B.K.R.I.S.T., Vidyanagar, Andhrapradesh ${ }^{i}$ \\ Professor, Dept.E.E.E., S.V.U.College of Engg, Tirupathi, Andhrapradesh ${ }^{2}$.
}

\begin{abstract}
This paper presents an improved method for multi distributed generation placement in distribution systems to reduce the real power loss and to improve the voltage profile. The location of nodes where the distributed generators should be placed is decided by a set of rules given by fuzzy expert system. The sizing of capacitors and distributed generators is modeled by the objective function to obtain minimum losses by using differential evolution technique. A case study with an IEEE-33 bus system is presented to illustrate the application of algorithm. A comparison with PSO is performed to show the improvement with proposed algorithm.
\end{abstract}

Keywords: Differential evolution (DE), Distributed generation (DG), Particle swarm optimization (PSO), Power loss, Voltage profile.

\section{Introduction}

Different definitions of DG have been proposed by Ackermann ect.al in 2001.According to them distributed generation can be defined as the installation and operation of electric power generation units connected directly to the distribution network or connected to the network on the customer side of meter. DG systems such as fuel cells, micro turbines, biomass, wind turbines, hydro turbines or photovoltaic arrays are environment friendly. These DGs are applied to a stand alone, a grid interconnected, a standby, a cogeneration etc. Distributed generation has a lot of benefits such as modular electric generation, increased reliability.

Distributed generation has both positive and negative impact on power quality. This will depend on the type and amount of DG, as well as power interfaces and control schemes used to connect these units to grid. The development of DGs will bring new changes to traditional power systems. The beneficial effects of DG mainly depend on its location and size. Selection of optimal location and size of DG is a necessary process to maintain the stability and reliability of existing system effectively before it is connected to power grid.

\section{Problem Formulation}

In this paper the main focus is on voltage improvement and reduction of power loss for a distribution system using multi DG units. First a load flow program calculates the power loss reduction by compensating the total real current for DG allocation at every node of distribution network. The loss reduction is then linearly normalized into [0.1] range with the largest reduction having a value of 1 and smallest one having a value of 0 . These power loss reduction indices along with p.u. nodal voltages are the inputs of Fuzzy expert system, which determines the most suitable node for DG installation by fuzzy inference. In this paper Backward- Forward method isuse dforload flow study.

This paper presents a fuzzy logic approach for optimal placement of DG and Differential evolution method for optimal size of DG. The results are compared with Particle swarm optimization method for optimal size of DG.
Algorithm for load flow solution using Backward-Forward method
1. Read the system, line data and bus data.
1) System data: number of buses, number of lines, reference bus or slack bus.
2) Line data: from bus, to bus, line resistance, line reactance.
3) Bus data: Bus number, Pload, Qload.
4) Read itermax, epsilon, base kva, base voltage \& initial voltages at all buses.

2. Form itagf, itagto, adjq and adjl vectors.

3. Initialize the Bus Voltages to $1+\mathrm{j} 0 \mathrm{p}$. u.

4. Calculate the Power Injections and Current Injections I[i] at all the buses.

$\mathrm{Ii}=\left(\mathrm{S}_{\mathrm{i}} / \mathrm{V}_{\mathrm{i}}\right)^{*}$

$\mathrm{S}_{\mathrm{i}}=$ complex power injection at bus $\mathrm{i}$

$\mathrm{V}_{\mathrm{i}}=$ complex voltage of bus $\mathrm{i}$ 
5. Initialize the iteration count $\mathrm{k}=1$.

6. Assign $\mathrm{I}[\mathrm{i}]$ old $=\mathrm{I}[\mathrm{i}]$ for all the buses.

7. During backward sweep calculate branch currents by using current injections as given below. for $\mathrm{i}=1$ :nline

$\mathrm{J}(\mathrm{i})=0$;

end

for $\mathrm{k}=$ nline: $-1: 1$

$\mathrm{p}=\operatorname{lp}(\mathrm{k})$;

$\mathrm{q}=\mathrm{lq}(\mathrm{k})$;

sum $=0.0$;

for $\mathrm{j}=\operatorname{itagf}(q): \operatorname{itagto}(q)$

$\mathrm{m}=\operatorname{adjl}(\mathrm{j})$;

end

sum $=\operatorname{sum}+\mathrm{J}(\mathrm{m})$;

end

$\mathrm{J}(\mathrm{k})=\operatorname{sum}-\mathrm{I}(\mathrm{q})$

Where $\mathrm{k}=1,2 \ldots . \mathrm{nline} ; \mathrm{q}=$ receiving end bus

8. In forward sweep calculate bus voltages from second bus to last bus as given below.

for $\mathrm{k}=1$ :nline

$$
\begin{aligned}
& \mathrm{p}=\mathrm{lp}(\mathrm{k}) ; \\
& \mathrm{q}=\mathrm{lq}(\mathrm{k}) ; \\
& \mathrm{E}(\mathrm{q})=\mathrm{E}(\mathrm{p})-(\mathrm{z}(\mathrm{k}) * \mathrm{~J}(\mathrm{k})) ; \\
& \text { End }
\end{aligned}
$$

9. Calculate the current Injections I[i] with the updated bus voltages.

10. If $\max \left(\left|I[i]^{\mathrm{k}+1}\right|-\left|\mathrm{I}[\mathrm{i}]^{\mathrm{k}}\right|\right)>$ tolerance, then advance the iteration count and go to step 6 .

11. Print the converged load flow solution and Stop.

In this work Fuzzy logic implementation for the identification of suitable nodes to place DG units is carried out using FIS editor. Inputs to FIS editor are Power loss index (PLI) and node voltage (VVV). Power loss obtained at every node from the load flow result is linearly normalized. Voltage is expressed in p.u. From the fuzzy logic toolbox the membership function details are depicted in figs 1, 2 and 3

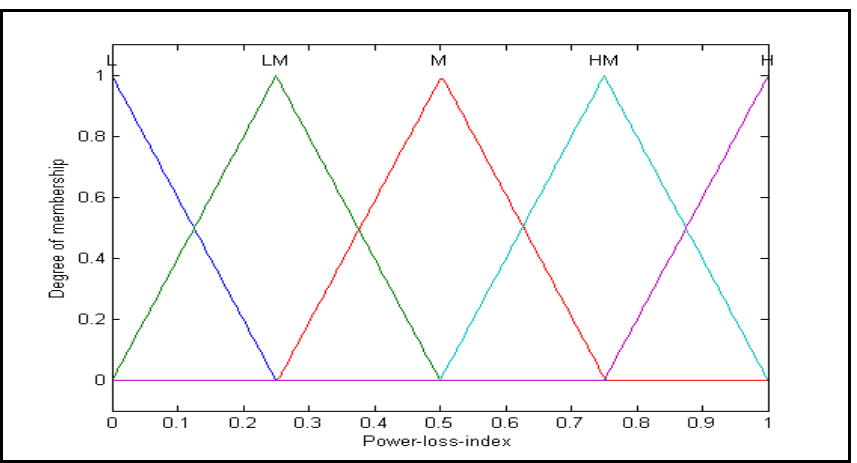

Fig 1: Membership function used for power loss index

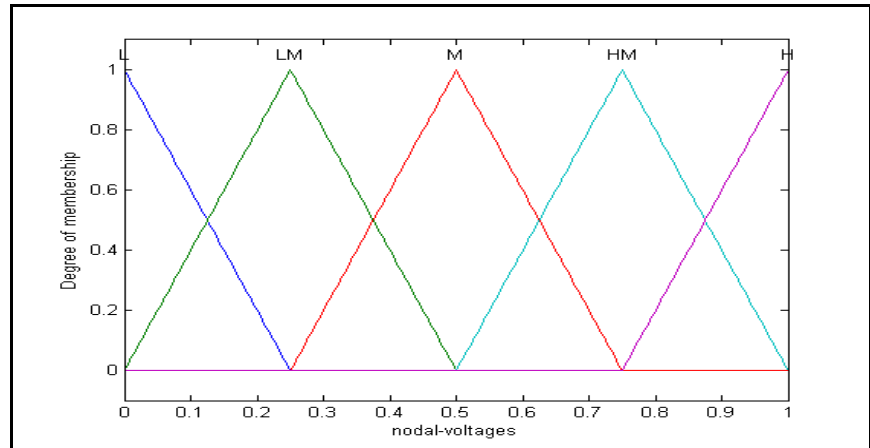

Fig 2: Membership function used for nodal voltages 


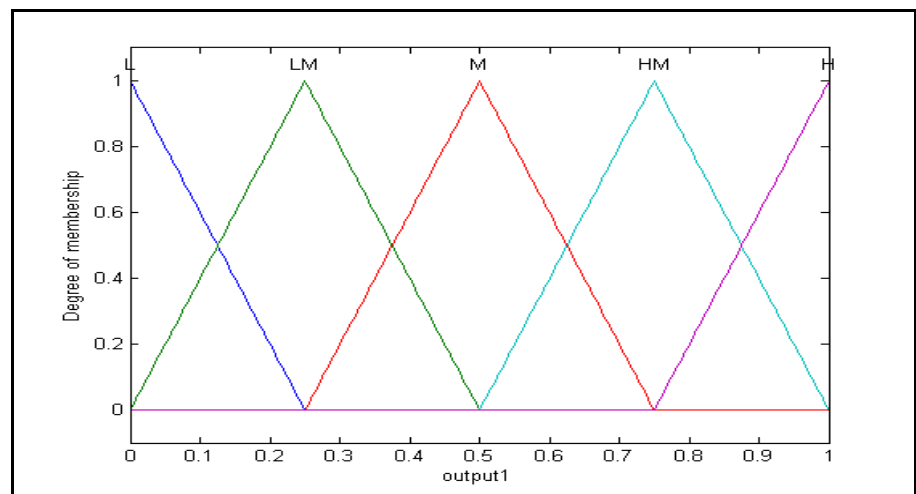

Fig 3: Membership function used for fuzzy output

\section{Differential Evolution Algorithm}

Differential evolution (DE) is a vector based evolutionary algorithm. It can be considered as a further development to genetic algorithm. It is a population based and derivative- free method. One advantage of differential evolution is that $\mathrm{DE}$ treats solutions as real number strings, thus no encoding and decoding is needed. Differential evolution consists of three main steps: mutation, crossover, selection.

\section{Algorithm}

1. Initialize $(\mathrm{x} * \mathrm{n})$ number of particles where $\mathrm{x}$ is population and $\mathrm{n}$ is number of $\mathrm{DG}$ devices.

2. Iteration count is set to one.

3. By placing all ' $n$ ' DG devices of each candidate node at respective candidate location, load flow analysis is performed.

4 Fitness value corresponding to each particle is evaluated.

Fitness $=\mathrm{P}_{\mathrm{L}}-\mathrm{P}_{\mathrm{L}}{ }^{\mathrm{DG}}$ for maximum loss reduction.

5. Set weight function $F$ and crossover probability $C_{r}$.

6. For each $\mathrm{x}$, randomly choose 3 distinct vectors $\mathrm{x}_{\mathrm{p}}, \mathrm{x}_{\mathrm{q}}$ and $\mathrm{x}_{\mathrm{r}}$

7. Generate a donor vector by the mutation scheme as per eq (5)

Where $\mathrm{F}$ is weight function

$$
\mathrm{v}_{\mathrm{i}}^{\mathrm{t}+1}=\mathrm{x}_{\mathrm{p}}{ }^{\mathrm{t}}+\mathrm{F}\left(\mathrm{x}_{\mathrm{q}}{ }^{\mathrm{t}}-\mathrm{x}_{\mathrm{r}}{ }^{\mathrm{t}}\right)
$$

8.Carry over crossover and select the minimum objective value.

9. Once the solution is updated, load flow analysis is performed; new fitness is calculated using equation (2)

$$
\mathrm{V}^{\min } \leq \mathrm{V}_{\mathrm{i}} \leq \mathrm{V}_{\mathrm{i}}^{\max }
$$

If new fitness is greater than pbest fitness then corresponding then corresponding candidate node is moved to pbest

particle.

10. Maximum of pbest fitness gives gbest fitness and corresponding candidate node is stored as gbest.

11. From pbest fitness, maximum fitness and average fitness are calculated. Error is calculated using equation

(3Error $=$ Maximum fitness - average fitness

If this error is less than a specified tolerance, go to step 9.

12. Increment the iteration count. If iteration count is not reached maximum, go to step 7 . 13. Gbest fitness gives maximum loss reduction and gbest candidate node gives optimal DG size.

\section{Particle Swarm Optimization Technique}

Particle swarm optimization is a computational method that optimizes a nonlinear and multidimensional problem. Population of birds or fish is known as swarm. Each candidate of swarm is known as particle. These particles move around in the search space searching for their goal, the place which best suits their needs given by a fitness function. Once a problem space is defined a set of particles spawned in it and their positions and velocities are updated iteratively according to specific PSO algorithm.

Every particle using eq (3) and (4) modifies its position to reach the global best position.

$\mathrm{V}_{\mathrm{i}}^{\mathrm{k}+1}=\mathrm{k}_{\mathrm{c}}\left[\mathrm{W} \mathrm{V} \mathrm{V}_{\mathrm{i}}^{\mathrm{k}}+\mathrm{C}_{1}\right.$ rand $_{\mathrm{i}}\left(\right.$ pbest $\left._{\mathrm{i}}-\mathrm{X}_{\mathrm{i}}\right)+\mathrm{C}_{2}$ rand $_{\mathrm{i}}\left(\right.$ gbest $\left.\left._{\mathrm{i}}-\mathrm{X}_{\mathrm{i}}\right)\right]$

$\mathrm{X}_{\mathrm{i}}^{\mathrm{k}+1}=\mathrm{X}_{\mathrm{i}}^{\mathrm{k}}+\mathrm{V}_{\mathrm{i}}^{\mathrm{k}+1}$

Where $\mathrm{k}_{\mathrm{c}}=$ constriction factor

$\mathrm{V}_{\mathrm{i}}^{\mathrm{k}}=$ velocity of a particle I in $\mathrm{k}^{\text {th }}$ iteration

$\mathrm{W}=$ inertia weight parameter

$\mathrm{C}_{1}, \mathrm{C}_{2}=$ weight factors

rand $_{1}$, rand $_{2}=$ random numbers between 0 and 1

$\mathrm{X}_{\mathrm{i}}^{\mathrm{k}}-$ position of particle in $\mathrm{k}^{\text {th }}$ iteration 


\section{Algorithm}

Step1. Initialize $\left(p^{*} n\right)$ number of particle, where $p$ is population size and $n$ is number of DG devices. Step2. $\left(p^{*} n\right)$ number of initial velocities are generated randomly between the limits.

Step 3. Iteration count is set to one.

Step 4. By placing all 'n' DG devices of each particle at respective candidate location, load flow analysis is performed.

Step 5. Fitness value corresponding to each particle is evaluated:

Fitness $=\mathrm{P}_{\mathrm{L}}-\mathrm{P}_{\mathrm{L}}{ }^{\mathrm{DG}}$ for maximum loss reduction initially all fitness is copied to pbest fitness. Maximum of pbest fitness gives gbest fitness which is a measure for maximum loss reduction, and thecorresponding particle represents gbest particles.

Step 6. New velocities for all the particles within the limits are calculated using eq (4). Particle positions are updated using eq (5).

Step 7. Once the particles are updated, load flow analysis is performed, new fitness is calculated. If new fitness is greater than pbest fitness then corresponding particle is moved to pbest particle. Step 8. Maximum of pbest fitness gives gbest fitness and corresponding particle is stored as gbest particle. Step 9. From pbest fitness, maximum fitness and average fitness values are calculated. Error is calculated using eq (6)

Error $=$ maximum fitness - average fitness

If this error is less than a specified tolerance, go to step 10.

Step 10. Increment the current iteration count. If iteration count is not reached maximum, go to step 6 .

Step 11. Gbest fitness gives maximum loss reduction and gbest particle gives optimal DG size.

\section{Result}

DE and PSO algorithms for DG sizing problem are simulated for an IEEE-33 bus system. Table 1 shows the Bus number of DG placement. DG size is obtained from DE and PSO method. Table 1 shows the comparative results of power loss and voltage profile before and after DG placement. From this table it can be observed that multi DG is very effective in power loss reduction and voltage improvement .The following figures shows the summary of results for multi DG placement.

Table 1: Summary of results for multi DG using DE and PSO

\begin{tabular}{|c|c|c|c|c|c|c|c|c|c|}
\hline \multirow{2}{*}{$\begin{array}{l}\text { No.of } \\
\text { DG }\end{array}$} & \multirow{2}{*}{\multicolumn{2}{|c|}{ Bus No. }} & \multicolumn{3}{|c|}{ Power loss (KW) } & \multirow{2}{*}{$\begin{array}{ll}\text { DG } & \text { size } \\
(\mathrm{KW}) & \end{array}$} & \multicolumn{3}{|c|}{ Voltage (p.u) } \\
\hline & & & $\begin{array}{l}\text { Without } \\
\text { DG }\end{array}$ & $\begin{array}{l}\text { With } \\
\text { DG }\end{array}$ & $\begin{array}{l}\text { \%loss } \\
\text { reduction }\end{array}$ & & $\begin{array}{l}\text { Without } \\
\text { DG }\end{array}$ & $\begin{array}{l}\text { With } \\
\text { DG }\end{array}$ & $\begin{array}{l}\% \quad \text { voltage } \\
\text { improvement }\end{array}$ \\
\hline \multirow[t]{2}{*}{1} & $\overline{D E}$ & 9 & 292.368 & 154.851 & 47.04 & 1819 & 0.8923 & 0.9817 & 10.02 \\
\hline & PSO & 9 & 292.368 & 154.851 & 47.04 & 1819 & 0.8923 & 0.9816 & 10.02 \\
\hline \multirow{4}{*}{2} & & 9 & \multirow[b]{2}{*}{292.368} & \multirow[b]{2}{*}{125.177} & \multirow[b]{2}{*}{57.18} & 970.1 & 0.8923 & 0.9803 & 8.97 \\
\hline & DE & 27 & & & & 1515.5 & 0.9242 & 0.9833 & 5.91 \\
\hline & \multirow[b]{2}{*}{ PSO } & 9 & \multirow[b]{2}{*}{292.368} & \multirow[b]{2}{*}{125.18} & \multirow[b]{2}{*}{57.18} & 970.2 & 0.8923 & 0.9804 & 8.97 \\
\hline & & 27 & & & & 1515.6 & 0.9242 & 0.9834 & 5.91 \\
\hline \multirow{6}{*}{3} & \multirow{3}{*}{$\mathrm{DE}$} & 9 & \multirow{3}{*}{292.368} & \multirow{3}{*}{110.335} & \multirow{3}{*}{62.26} & 969.925 & 0.8923 & 0.9802 & 9.85 \\
\hline & & 27 & & & & 772.613 & 0.9242 & 0.9831 & 6.37 \\
\hline & & 32 & & & & 690.079 & 0.8896 & 0.9716 & 9.22 \\
\hline & \multirow{3}{*}{ PSO } & 9 & \multirow{3}{*}{292.368} & \multirow{3}{*}{110.34} & \multirow{3}{*}{62.25} & 969.924 & 0.8923 & 0.9803 & 9.85 \\
\hline & & 27 & & & & 772.615 & 0.9242 & 0.9832 & 6.37 \\
\hline & & 32 & & & & 690.08 & 0.8896 & 0.9716 & 9.22 \\
\hline
\end{tabular}

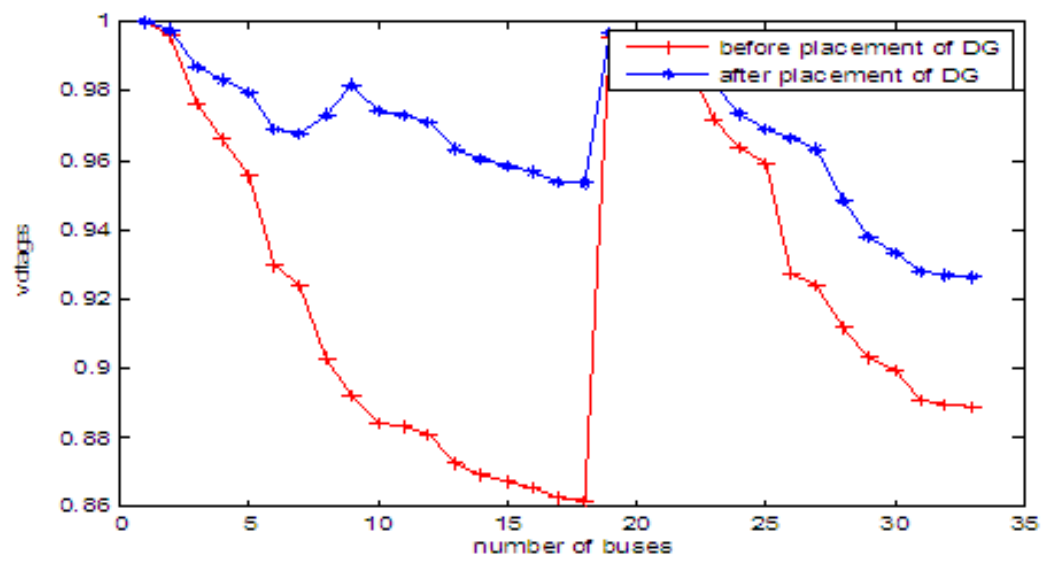

Fig4: Bus voltages for 1 DG 


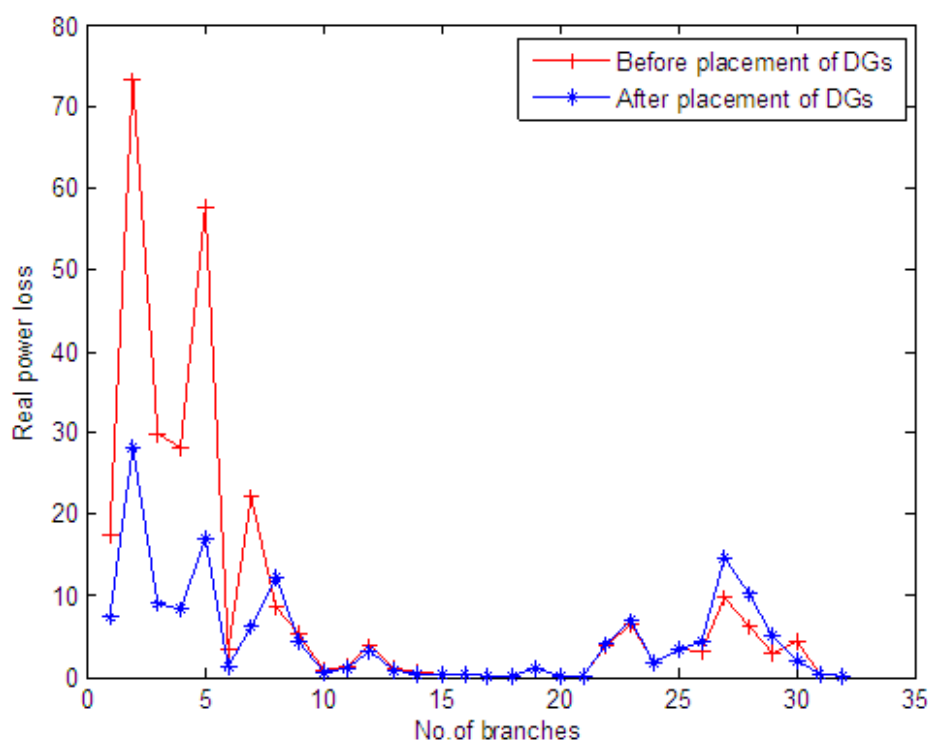

Fig 5: power loss for $1 \mathrm{DG}$

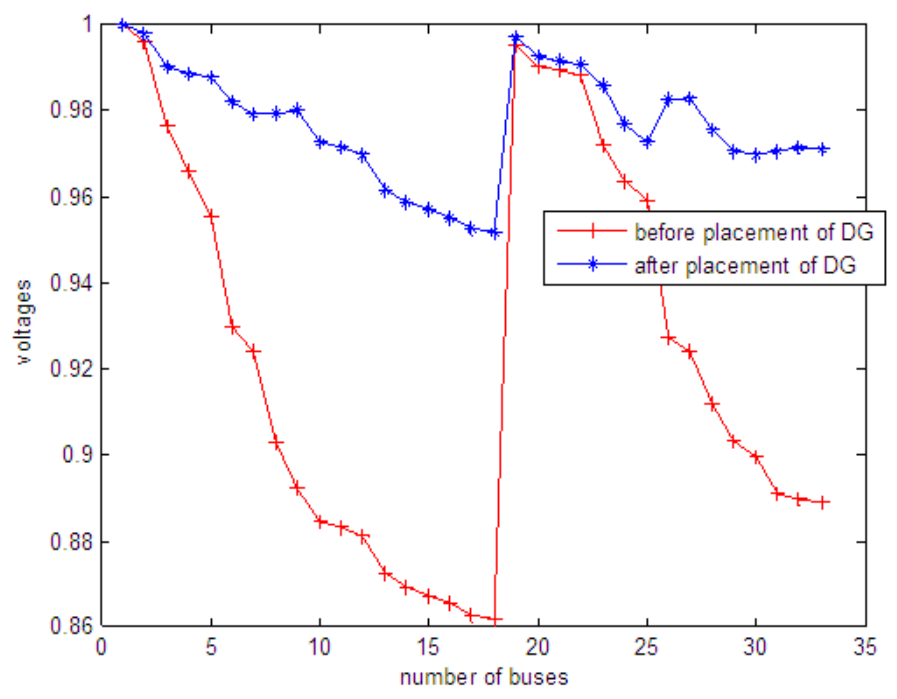

Fig 6: Bus voltages for 3 DG

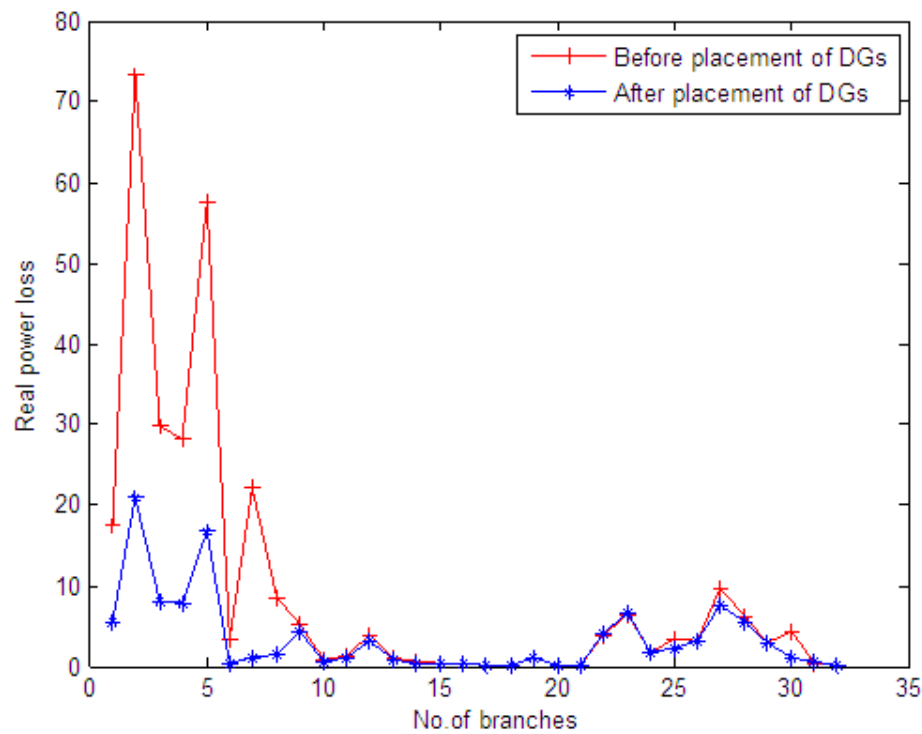

Fig7: power loss for $3 \mathrm{DG}$ 


\section{Conclusions}

It is observed that there is a significant decrease in real and reactive power losses with multi DG placement. The variation in real power losses with two evolutionary algorithms is presented. There is also presented the effect of multi DG units on system voltages. It is also observed that the result with two evolutionary algorithms is same. But the solution converges fast in Differential evolution algorithm.

\section{References}

[1]. Rajendra Prasad Payasi, Ashish k.Singh, Devender singh "Review of Distributed Generation planning, objectives, constraints, algorithms", International journal of engineering science \& technology, vol.3,2011.

[2]. A.M.E.I.Zonkoly, "Optimal placement of multi distributed generation units including different load models using particle swarm optimization", Swarm and evolutionary computation, 2011.

[3]. Rajkumar singh, S.K.Goswamy, "A genetic algorithm based approach for optimal allocation of distributed generations in power system for voltage sensitive loads", ARPN journal of engineering and applied sciences, 2009

[4]. Tuba Gozel, M.Hakanhocaoglu, "An analytical method for sizing and siting of DGs in radial systems", IEEE transactions on power delivery, pp 912-918, vol.79, issue 6, June 2009.

[5]. Chang, G.W, Wien-Chang Chang, "Fuzzy logic and Immune based algorithm for placement and sizing of shunt capacitor banks in a distorted power network", IEEE transactions on power delivery, vol.26, issue 4, Oct 2011.

[6]. D.Q.Hung and N.Mithulananthan," Multiple distributed generator placement in primary distribution networks for loss reduction", IEEE transactions on Industrial electronics, vol.60,No.4, pp 1700-1708, April 2013. 